\title{
GESTÃO DE RESÍDUOS SÓLIDOS URBANOS NA CIDADE DO PORTO (PORTUGAL): UM EXEMPLO DE PRÁTICA SUSTENTÁVEL?
}

\author{
Lívia Corrêa Silva \\ Graduanda em Engenharia Ambiental - Escola Politécnica - UFRJ \\ liviacorrea@poli.ufrj.br \\ Beatriz Costa Roza \\ Graduanda em Engenharia Ambiental - Escola Politécnica - UFRJ \\ biaroza@poli.ufrj.br \\ Régis Rathmann \\ Doutor em Planejamento Energético pela Universidade Federal do Rio de Janeiro - UFRJ \\ Professor da Universidade Federal do Rio de Janeiro - UFRJ \\ rathmann@ppe.ufrj.br
}

\section{RESUMO}

Em uma sociedade que cultua o consumo desenfreado de bens de curto tempo de utilização, faz-se necessário o uso de Sistemas de Gestão de Resíduos Sólidos que se comprometam com o desenvolvimento sustentável e busquem a viabilidade econômica, a equidade social e a amenização dos impactos ambientais. Este trabalho visou, por meio do estudo das políticas e sistemas de gestão referentes aos resíduos sólidos urbanos, em Portugal, analisar práticas de sustentabilidade aplicadas e sua real efetividade. Verificou-se, primeiramente, que um dos princípios que rege a política europeia de resíduos, a hierarquia de gestão de resíduos sólidos, carece de embasamento técnico e científico, não garantindo, necessariamente, benefícios ambientais, sociais e econômicos entre as opções de tratamento. A sustentabilidade econômica dos sistemas de gestão não vem sendo alcançada, principalmente pela dificuldade na cobrança de tarifas que efetivamente reflitam a quantidade de resíduos per capita. Analisou-se também, com base nos Relatórios de Sustentabilidade da Lipor, empresa que gere os resíduos sólidos urbanos do Grande Porto, o projeto de reduções voluntárias de emissões de $\mathrm{CO}_{2}$. Verificou-se que a não contabilização da reciclagem no seu inventário de emissões pode refletir em uma transferência de emissões para outras empresas, além de reduções de custos para a Lipor, visto que a triagem de recicláveis é menos onerosa que outros tratamentos, como a incineração.

Palavras-chave: Análise da sustentabilidade; Gestão de resíduos sólidos urbanos; Portugal.

\section{URBAN SOLID WASTE MANAGEMENT IN THE CITY OF PORTO (PORTUGAL): IS THIS A PRACTICAL EXAMPLE OF SUSTAINABILITY?}

\section{ABSTRACT}

A society based on wasteful consumption of short-lifespan goods, requires Solid Waste Management Systems that follow the principles of Sustainable Development and that are economically affordable, socially acceptable, and environmentally effective. In this work, we went through the study of policies and management systems related to municipal solid waste in Portugal, so as to analyze sustainability practices implemented and their efficacy. We found as a fundamental principle of European politics of waste, that the hierarchy of solid waste management lacks technical and scientific knowledge, not ensuring necessary, environmental, social, and economic benefits between the treatment options. The economic sustainability of the management has not been achieved mainly due to the difficulty in defining fees that effectively reflect the amount of waste per capita. We also analyzed, based on the Sustainability Report of Lipor (a company that manages the municipal solid waste from the Grande Porto), the project of voluntary reductions of $\mathrm{CO}_{2}$ emissions. It was found that not accounting for the recycling process in their emissions inventory may result in a transfer of emissions to other companies and in cost savings for Lipor, since the sorting of recyclables is less expensive than other treatments, such as incineration.

Keywords: Municipal solid waste management; Portugal; Sustainability analysis. 


\section{INTRODUÇÃO}

A ampliação das discussões acerca da relação entre o desenvolvimento das nações e a preservação do meio ambiente, que surge a partir da década de 1970, bem como das relações entre as fontes de recursos naturais renováveis, e não-renováveis, com a sustentabilidade dos processos produtivos, se reflete na sociedade de diversas formas, inclusive na produção científica que aborda essas temáticas. Nas várias áreas do conhecimento que tangenciam o assunto, observam-se tendências distintas quanto às abordagens; algumas com maior nível de "radicalismo" quanto à preservação dos recursos, e outras buscando um equilíbrio entre o uso e a conservação dos recursos, com vistas à ampliação dos processos de desenvolvimento das nações. Neste contexto, pode-se dizer que as mudanças paradigmáticas que vão orientando as atividades humanas e a evolução do entendimento conceitual acerca do desenvolvimento sustentável, são questões que estão imbricadas.

Aprofundando esta ideia, as tratativas apontam um paradigma estabelecido, centrado no ser humano, antagônico a um paradigma centrado no meio ambiente, que é buscado como a situação ideal para as relações entre os humanos e a natureza. Entre os dois, Gladwin, Kennelly e Krause (1995) e Egri e Pinfield (2001) enfatizam a existência de um terceiro paradigma, que sintetiza os demais e se coloca como uma situação intermediária ou de transição entre as visões mais radicais. Ainda Shrivastava (1995), Purser, Park e Montuori (1995) e Hopwood, Mellor e O’Brien (2005) não mencionam a existência de um terceiro paradigma, mas apontam possibilidades de situações intermediárias entre as visões extremadas que apresentam.

Concomitante ao estabelecimento de novos indicativos paradigmáticos ocorre a construção de um conceito de desenvolvimento sustentável, que possa ser mundialmente aceito. Para Mebratu (1998), a Conference on Human Environment, ocorrida em Estocolmo em 1972, representa um passo em direção a esta construção. Mesmo que as ligações entre o meio ambiente e as iniciativas desenvolvimentistas ainda não tinham aparecido durante a conferência, havia indicativos de que a forma como que o crescimento econômico estava sendo construído precisava mudar.

Tal constatação está alinhada ao modelo industrial econômico vigente, onde o consumo acelerado dos recursos naturais, para atender a produção de bens e serviços de uma população com taxas de crescimento elevadas, evidencia a insustentabilidade dos padrões aplicados pela sociedade (Sachs, 1993; Mebratu, 1998; OECD, 2001). Neste sentido, uma importância relativa pode ser dada ao Relatório Brundtland elaborado pela World Commission on Environment and Development (WCED, 1987). Este, quando constrói o conceito de que "[...]desenvolvimento sustentável é assegurar a satisfação das necessidades do presente, sem comprometer a habilidade das futuras gerações de satisfazerem suas próprias necessidades[...]", abre espaço para o questionamento sobre como se atingir essa tipologia de desenvolvimento. Neste caso, evidencia-se, como satisfação às necessidades o atendimento a uma demanda que, diante de um modelo econômico que preconiza o consumo constante de bens dito "descartáveis", leva a que se questione o que fazer com os resíduos.

Em sentido amplo, os resíduos podem ser compreendidos como externalidades negativas, que só deixariam de existir caso não houvesse atividade econômica (Pearce e Turner, 1995), o que é incompatível com as necessidades produtivas do modelo econômico vigente. A redução da poluição a níveis aceitáveis, em que o custo social não ultrapasse os benefícios gerados pela atividade, é o ponto chave para o alcance da sustentabilidade (McDougall et. al., 2001). A geração de resíduos é reflexo de toda e qualquer atividade, e por isso, compreender os princípios de sua geração permite avaliar as melhores oportunidades de sua gestão.

Neste contexto, este trabalho parte da realização de um estudo de caso de gestão de resíduos sólidos urbanos (RSU), com vistas a avaliar se o desenvolvimento, e as práticas utilizadas, colaboram para a construção de uma iniciativa economicamente viável, socialmente justa e ecologicamente correta.

Com vistas a responder ao presente objetivo, inicialmente no item 1 será feito um panorama dos RSU em Portugal, de forma a esclarecer as políticas que regem a elaboração de planos e sua gestão. Já no item 2 será apresentado o estudo de caso da Lipor Serviço Intermunicipalizado de 
Gestão de Resíduos, localizada no Grande Porto/Portugal, que tem como foco a descrição das ações ambientais. No item 3, objetiva-se analisar criticamente as ações ambientais da empresa, de forma a diagnosticar que medidas efetivamente resultam na mitigação dos impactos negativos ao meio ambiente. Finalmente, no item 4 serão descritas as conclusões do estudo.

\section{UTILIZAÇÃO E DESTINAÇÃO DOS RESÍDUOS SÓLIDOS EM PORTUGAL}

O Plano Estratégico para os Resíduos Sólidos Urbanos (Persu) foi aprovado em 1997 pelo governo português, estabelecendo os primeiros passos na concretização de uma política de resíduos. Este instrumento de planejamento, que se tornou referência na área dos Resíduos Sólidos Urbanos (RSU), permitiu o encerramento dos lixões ${ }^{1}$, a criação de sistemas multimunicipais e intermunicipais de gestão de RSU, a construção de infraestrutura de valorização e eliminação e a criação de sistemas de coleta seletiva ${ }^{2}$ multimaterial. A Figura 1 mostra o encerramento das lixeiras em 2002 e as mudanças nas opções de gestão dos RSU em Portugal, como o Persu.

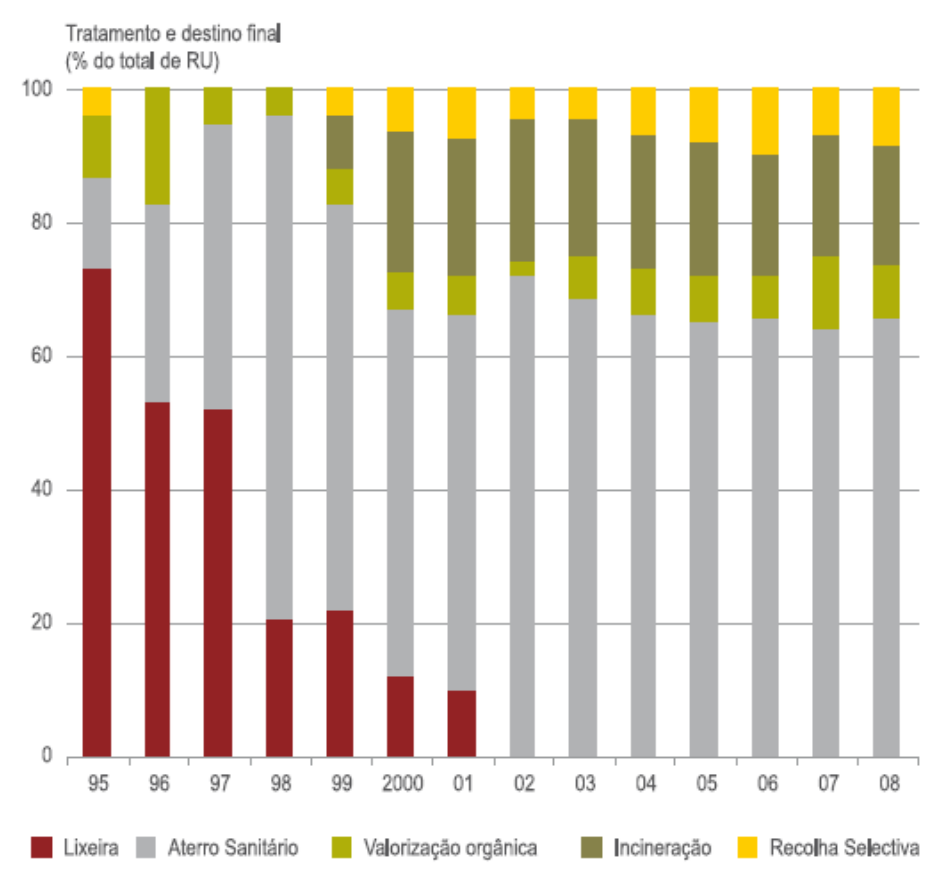

Figura 1: Evolução da gestão de RSU em Portugal

Fonte: REA, 2008 e APA, 2009.

Apesar de eliminação dos lixões, grande parte dos RSU ainda é destinada aos aterros, o que não vai de encontro com as metas previstas para 2005, no PERSU, nas quais eram pretendidas $23 \%$ de disposição em aterro, $23 \%$ de incineração, $25 \%$ de reciclagem, $25 \%$ de compostagem e $5 \%$ de redução. A Figura 2 apresenta um comparativo entre as metas do PERSU e a situação verificada em 2005.

\footnotetext{
1 Descarga indesejável no solo, em que os resíduos são lançados de forma indiscriminada e não existe qualquer controle posterior.

2 Coleta realizada de forma separada, de acordo com um programa pré-estabelecido, com vistas à futura valorização (PERSU II)
} 


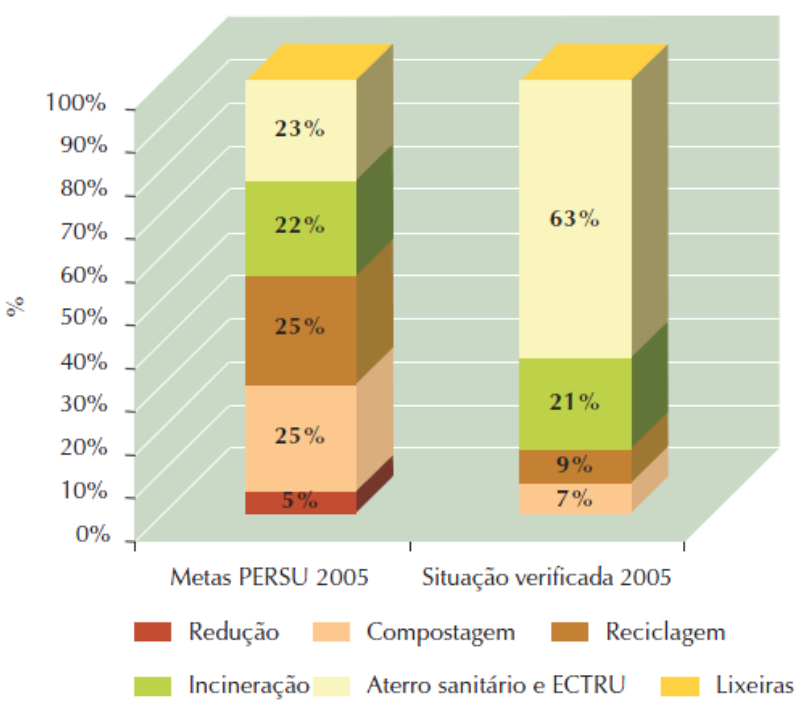

Figura 2: Metas do PERSU I e a situação verificada em 2005

Fonte: PERSU II, 2006.

Além do não cumprimento de metas, o surgimento de novas legislações e diretivas europeias sobre RSU tornaram necessária a revisão do plano. Publicado em 2006, o PERSU II define prioridades e estabelece metas para o período de 2007 a 2016, incorporando em seus objetivos as estratégias em nível europeu e nacional. Entre essas se destacam:

- Estratégia Temática de Prevenção e Reciclagem de Resíduos e Estratégia Temática sobre a Utilização Sustentável dos Recursos Naturais, provenientes do $6^{\circ}$ Programa Comunitário de Ação em Matéria de Ambiente, no qual se preconizam os princípios do poluidor-pagador, da precaução e da ação preventiva, e da correção da poluição na fonte, e da Diretiva 2006/12/CE que pretende tornar a UE uma sociedade da reciclagem;

- O novo Regime Geral de Gestão de Resíduos, aprovado pelo Decreto-Lei 178/2006, que estabeleceu mudanças e simplificações na gestão de RSU, além de constituir um novo regime econômico-financeiro com o estabelecimento de taxas de gestão de resíduos e a criação de um "mercado organizado de resíduos";

- A incorporação da Estratégia Nacional para o Desvio de Resíduos Urbanos Biodegradável de Aterro (Enrrubda), aprovada em 2003, de acordo com a Diretiva 199/31/CE, em que foi estabelecida como meta a redução de matéria orgânica em aterro por meio da ampliação da valorização orgânica;

- O cumprimento dos objetivos de reciclagem e valorização, decorrentes das Diretiva 94/62/CE e 2004/12/CE, relativas à gestão de embalagens e resíduos de embalagens;

- Ajuste da política de RSU com o compromisso de redução das emissões de gases efeito estufa, assumido no âmbito do Protocolo de Quito e no Plano Nacional para as Alterações Climáticas (PNAC).

Em linhas gerais, o Persu tem como objetivo prevenir e reduzir a produção de RSU; promover o life cycle thinking na gestão dos resíduos; buscar a sustentabilidade dos sistemas de gestão por meio de sistemas tarifários que reflitam os custos; reduzir a quantidade de resíduos biodegradáveis em aterros.

A análise de sustentabilidade do sistema requer uma análise do ciclo de vida (ACV), que é uma ferramenta de auxílio da tomada de decisão que permite avaliar os impactos causados por um produto ao longo de sua "vida". Por esse motivo, a Estratégia Temática de Prevenção e Reciclagem 
sugere a introdução da ACV na definição de política e racionalização da legislação da União Europeia (UE), em matéria de resíduos.

Integrante da União Europeia, Portugal segue as políticas desenvolvidas pela Comunidade. A nova Diretiva dos Resíduos n²008/98/CE, substituta da Diretiva 2006/12/CE, que rege o Planejamento e Gestão de Resíduos, foi transposta para Portugal pelo Decreto-Lei 178/2006, sendo este responsável pela criação da Política Nacional de Resíduos. Nesta nova diretiva se estabelece uma hierarquia de resíduos e se define uma ordem prioritária de ação, qual seja (Figura 3): 1) Prevenção; 2) Redução; 3) Preparação para a reutilização; 4) Reciclagem; 5) Outros tipos de valorização, por exemplo, a energética; e 6) Eliminação.

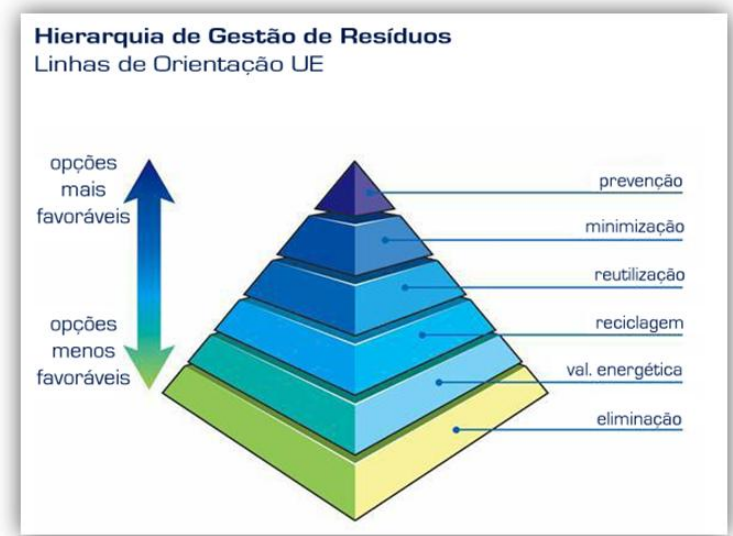

Figura 3: Hierarquia da gestão de resíduos Fonte: Lipor, 2010.

Contrariando a prioridade de ações estabelecidas pela Diretiva 2008/98/CE, PERSU (2006) concluiu que a reciclagem é o componente com maior potencial de redução indireta de emissões $\left(0,41 \mathrm{t} \mathrm{CO}_{2}\right.$ eq/ $\left.\mathrm{t}_{\text {reciclada }}\right)$, seguido pela valorização energética, via incineração, e pela substituição de fertilizantes por composto de valorização orgânica com $0,18 \mathrm{t} \mathrm{CO}_{2} \mathrm{eq} / \mathrm{t}_{\text {incinerada }}$ e $0,02 \mathrm{t} \mathrm{CO}_{2} \mathrm{eq} / \mathrm{t}_{\text {valorizada, }}$, respectivamente (Figura 4).

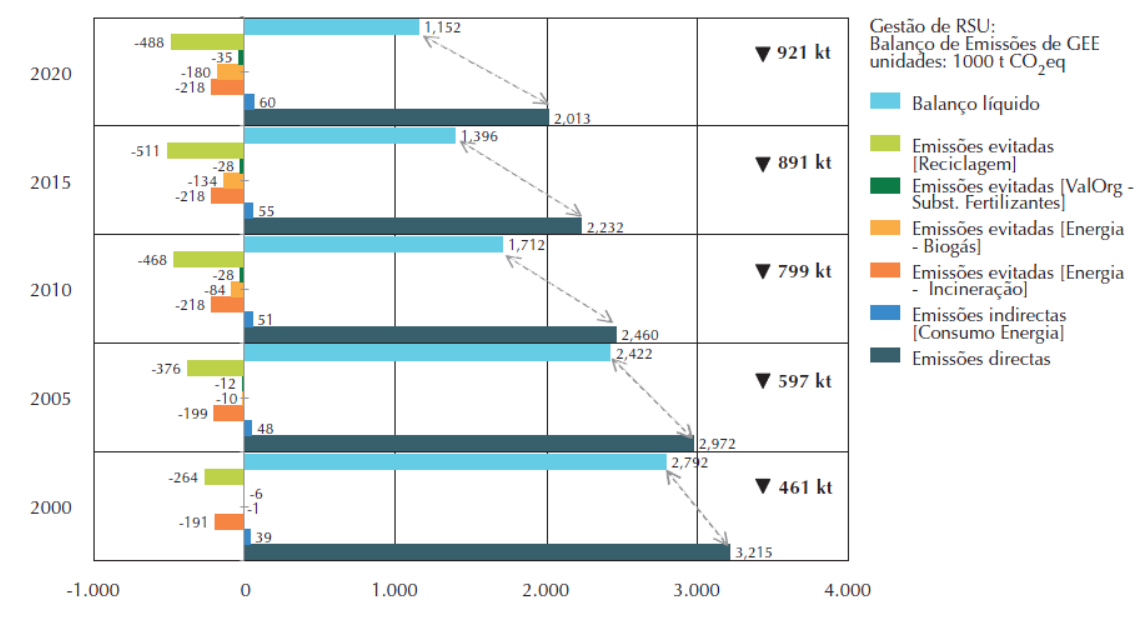

Figura 4: Balanço das emissões de GEE na gestão e no tratamento de RSU

Fonte: Persu II, 2006

Os RSU em Portugal são de responsabilidade das autarquias (municípios) e podem ser geridos por sistemas multimunicipais, que servem dois ou mais municípios, e possuem investimentos prioritariamente do Estado devido a interesses nacionais ou por sistema municipais, 
cujos investimentos são provenientes das próprias Câmaras Municipais. Nos sistemas municipais, pode haver associações de municípios formando Sistemas Intermunicipais. Segundo a Agência Portuguesa do Ambiente (APA), em 2009, havia 13 sistemas multimunicipais e 12 intermunicipais conforme apresentado pela Figura 5.
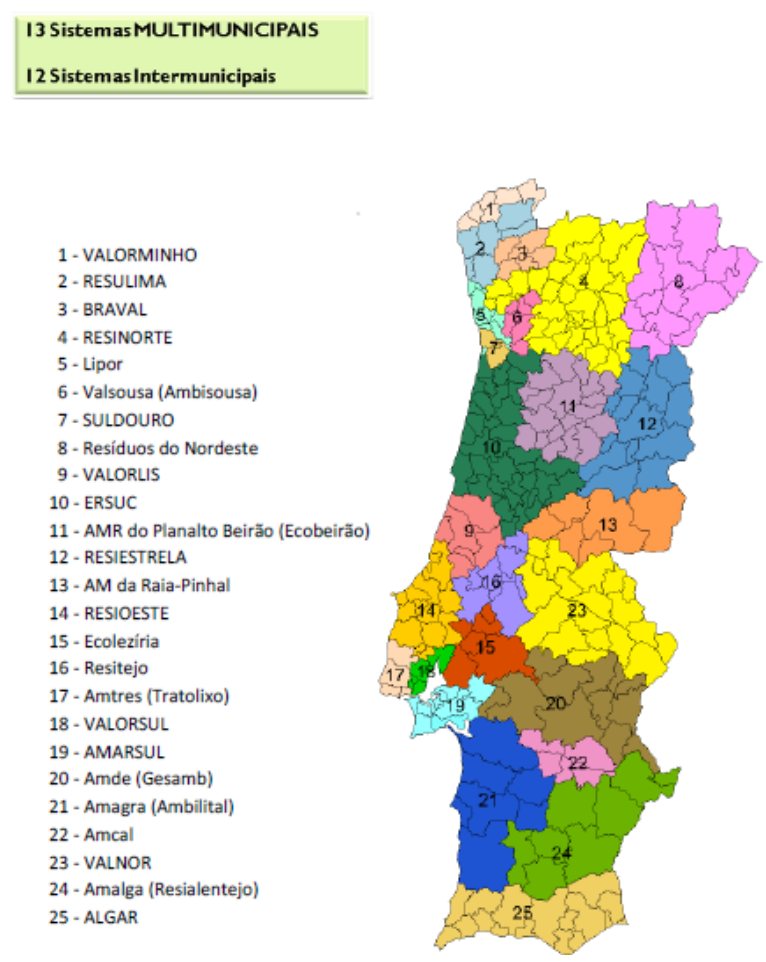

Figura 5: Sistemas de Gestão de RSU em Portugal

Fonte: APA, 2009

Cada sistema possui uma infraestrutura de tratamento e eliminação diferente. Os dois principais sistemas são responsáveis pelos dois grandes centros urbanos do país. Grande Lisboa, onde os RSU são geridos pela Valorsul ${ }^{3}$, e o Grande Porto, que é área gerida pela Lipor. A Tabela 1 apresenta a infraestrutura de RSU atuais e previstas no país em 2009.

Tabela 1: Infraestrutura de RSU atuais e previstas no país em 2009

\begin{tabular}{ccccc}
\hline Infraestrutura & Previstos & Construção & Exploração & Total \\
\hline Aterro & 7 & 1 & 34 & 42 \\
Valorização Orgânica & 7 & 8 & 9 & 24 \\
Valorização Energética & - & - & 2 & 2 \\
Estações de Transferência & - & - & 81 & 81 \\
Estação de Triagem & 4 & - & 29 & 33 \\
Ecocentros & 1 & - & 189 & 190 \\
Ecopontos & - & - & 31.068 & 31.068 \\
\hline
\end{tabular}

Fonte: APA, 2009

\footnotetext{
${ }^{3}$ A Valorização e Tratamento de Resíduos Sólidos das Regiões de Lisboa e do Oeste, S.A (Valorsul). - é a empresa responsável pelo tratamento e valorização de resíduos sólidos urbanos em 19 municípios da Grande Lisboa e da Região Oeste. Sua área de intervenção corresponde a menos de $4 \%$ da área total do país, entretanto valoriza mais de um quinto de todo o lixo doméstico produzido em Portugal.
} 
Os aterros são infraestruturas de engenharia, preparados para disposição de resíduos com sistemas de controle e monitoramento de gases e lixiviados. A captação do biogás, proveniente da decomposição anaeróbia dos resíduos, pode permitir um aproveitamento energético.

A valorização orgânica define-se como a utilização da fração orgânica contida nos resíduos para produção de composto por meio da degradação biológica aeróbia para ser utilizado como corretivo agrícola ou para produção de biogás pela digestão anaeróbia que pode ser também complementada pela compostagem.

Entende-se por valorização energética, a prática de incineração na qual o alto poder calorífico dos resíduos pode ser convertido em energia térmica, mecânica ou elétrica por meio de sistemas de caldeiras, turbinas e geradores.

Segundo o Decreto-Lei 239/97, uma estação de transferência é uma instalação onde os resíduos são descarregados como o objetivo de prepará-los para serem transportados para outro local de tratamento, valorização ou eliminação.

Os ecopontos, os ecocentros e as estações de triagem constituem a infraestrutura da valorização multimaterial. Enquanto o ecoponto é um conjunto de contentores preparados para disposição multimaterial de resíduos para reciclagem, o ecocentro é uma área vigiada destinada à recepção de resíduos para reciclagem com volume superior àqueles destinados aos ecopontos, e com eventual mecanização para preparação dos resíduos para ser encaminhados à reciclagem. Já a estação de triagem é instalação onde os resíduos são separados, mediante processos manuais ou mecânicos, nos materiais constituintes destinados a valorização ou a outras operações de gestão.

A seguir é apresentado o estudo de caso da Serviço Intermunicipalizado de Gestão de Resíduos do Grande Porto (Lipor).

\section{ESTUDO DE CASO DA LIPOR, SERVIÇO INTERMUNICIPALIZADO DE GESTÃO DE RESÍDUOS DO GRANDE PORTO}

Neste capítulo, será apresentado o estudo de caso da Lipor, localizada no Grande Porto/Portugal, tendo como foco a especificação das ações ambientais. As informações foram obtidas por meio de visitas e entrevistas à empresa. Além disso, os relatórios corporativos e de sustentabilidade da Lipor foram utilizados como fonte da pesquisa e/ou complementação de dados obtidos in loco.

\subsection{Atribuições e estrutura operacional}

A Lipor é a entidade responsável pela gestão, valorização, recuperação e destinação final dos resíduos sólidos urbanos produzidos pelos oito Municípios que a integram, quais sejam: Espinho, Gondomar, Maia, Matosinhos, Porto, Póvoa de Varzim, Valongo e Vila do Conde.

A empresa possui em seu sistema de gerenciamento de RSU, uma Central de Triagem, uma Central de Valorização Energética (CVE), um Aterro Sanitário para o Confinamento Técnico e uma Central de Valorização Orgânica (CVO). A Figura 6 esquematiza as possíveis rotas de tratamento e disposição final dos resíduos, de acordo com sua tipologia, que varia devido à fonte geradora e à atitude de seu gerador. 


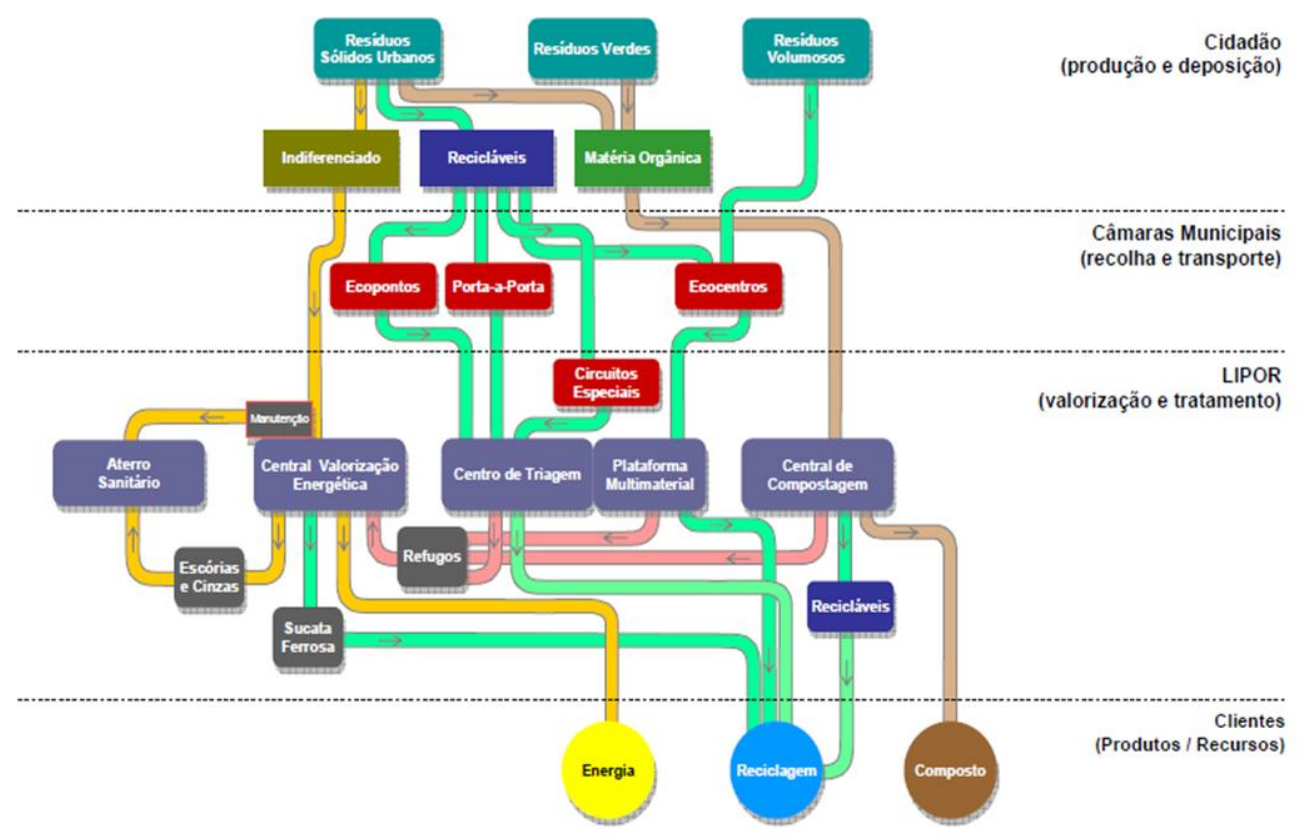

Figura 6: Dinâmica dos RSU e atribuições

Fonte: Lipor, 2010

Após receber os diferentes tipos de RSU, estes são classificados como indiferenciados, recicláveis e matéria orgânica. Indiferenciados são os resíduos que foram descartados sem uma separação que poderia viabilizar a reciclagem orgânica ou material. A coleta destes resíduos é feita, principalmente, no circuito porta a porta ou em lixeiras coletivas (contêineres). Estes resíduos serão destinados à Valorização Energética, via Incineração. Cabe ainda destacar a presença do aterro como uma "peça" de auxílio à CVE, recepcionando as escórias resultantes do processo, além dos volumes que venham a ultrapassar a capacidade da CVE.

Os ecopontos são contêineres dispostos nas ruas, de modo que a população possa destinar os resíduos como plásticos, metais, vidros e papéis para reciclagem. Já os ecocentros são responsáveis pela recepção de resíduos mais complexos, mas que também podem ser reciclados, tais como óleos, pneus, eletrodomésticos, entre outros. Além disso, há iniciativas de coleta seletiva porta a porta. O processo de triagem destes resíduos é de responsabilidade da Lipor, que os encaminha para os órgãos competentes para a comercialização e valorização destes como insumo. Por sua vez, a matéria orgânica que será destinada à compostagem provém de um processo operacional denominado operação Restauração 5 Estrelas, na qual são coletados restos de alimentos de cantinas e restaurantes das cidades, além dos resíduos verdes provenientes de parques e cemitérios. $\mathrm{O}$ composto gerado na Central de Valorização Orgânica é vendido pela própria Lipor.

\subsection{Projetos}

A Lipor intenciona ser uma organização de referência na valorização de recursos, responsabilidade social e ecoeficiência. Para isto, desenvolve diversos projetos de cunho social e ecológico, tais como projetos de educação e sensibilização ambiental e recuperação de passivos ambientais, além de projetos ligados à sustentabilidade, como a Estratégia 2M e PAYT (Pay as you throw), que serão descritos a seguir.

\subsubsection{Estratégia $2 \mathrm{M}$}

A Estratégia 2M (menos resíduos, menos carbono) é um dos projetos no qual a empresa procura embasar seu comprometimento com o alcance do desenvolvimento sustentável. A presente 
preocupação com o aquecimento global colocou as emissões de carbono, principalmente gás carbônico $\left(\mathrm{CO}_{2}\right)$, como um dos parâmetros para avaliar os impactos ambientais. Neste sentido, a Lipor, por meio da Estratégia 2M, prevê metas de redução tendo como base três eixos de ação, esquematizados conforme a Figura 7.

\begin{tabular}{|c|c|c|}
\hline EIXO 1 & EIXO 2 & EIXO 3 \\
\hline Conhecimento & Acção & Mobilização \\
\hline $\begin{array}{l}\text { Conhecer o perfil } \\
\text { de emissões } \\
\text { de GEE da Lipor }\end{array}$ & $\begin{array}{l}\text { Reduzir emissões } \\
\text { próprias e compensar } \\
\text { emissões inevitáveis }\end{array}$ & $\begin{array}{l}\text { Mobilizar para a } \\
\text { redução de resíduos } \\
\text { e de emissões } \\
\text { de carbono }\end{array}$ \\
\hline
\end{tabular}

Figura 7: Eixos de intervenção

Fonte: Lipor 2M, 2010.

O "eixo do conhecimento" baseia-se na produção e divulgação de informação a respeito das emissões de gases de efeito estufa (GEE) pelas atividades da Lipor, e sobre o potencial de emissões evitadas por meio da gestão de resíduos. Tanto a quantificação destas emissões, quanto a implementação das medidas para as reduções, demonstram a disposição da Lipor em mitigar o impacto ambiental de suas atividades, minimizando assim o respectivo efeito no clima.

A Figura 8 mostra que a contabilização das emissões é feita levando-se em conta a recolha (coleta), as atividades de tratamento (valorização) e as atividades suporte (energia e mobilidade). Ou seja, consideram-se as emissões diretas (provenientes das atividades produtivas da empresa), as emissões indiretas (associadas à produção de energia consumida pela Lipor) e as contabilizações opcionais.

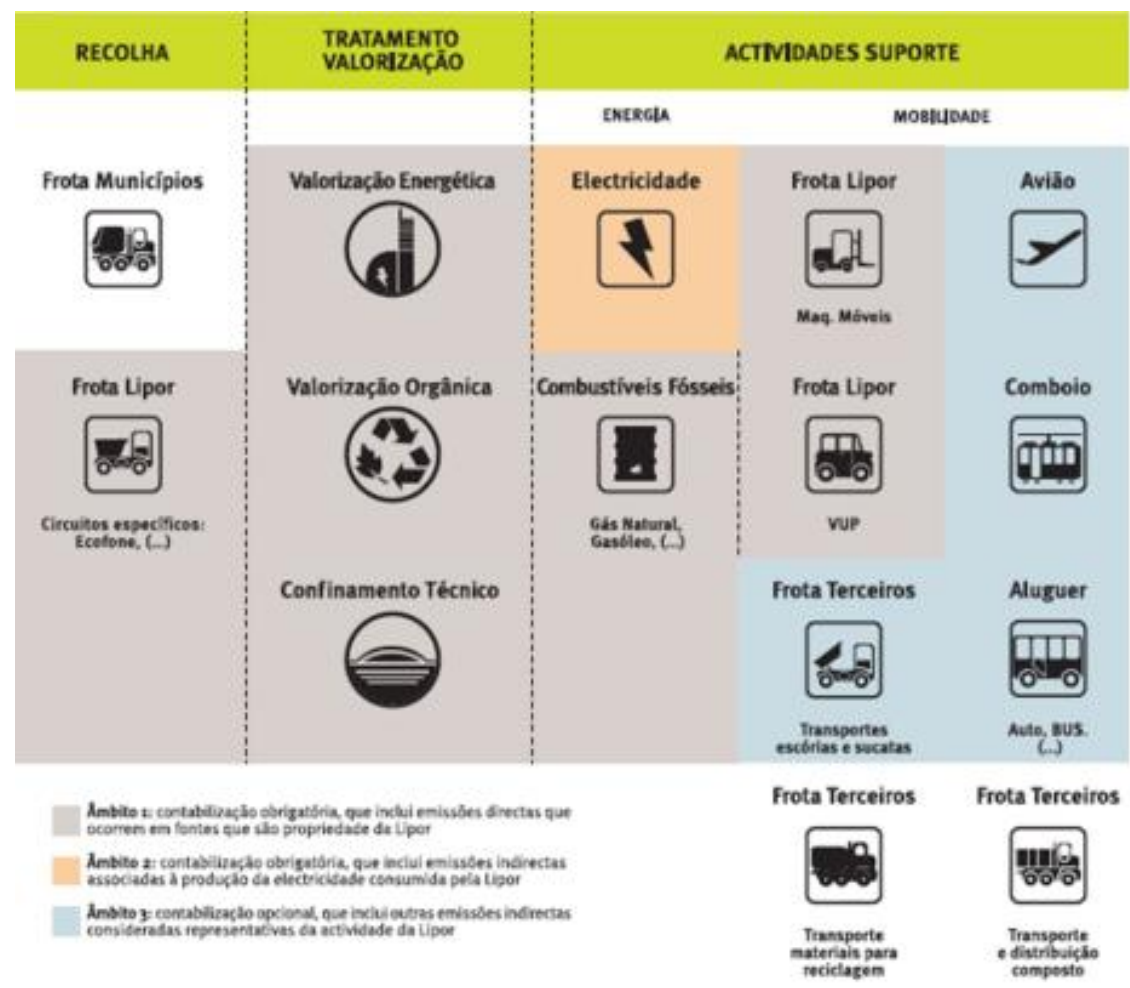

Figura 8: Âmbito de contabilização do inventário de emissões de GEE pela Lipor Fonte: Lipor 2M, 2010

Por meio de tais contabilizações, pôde-se notar que a maior parte das emissões da empresa provém das atividades de tratamento de RSU. Em 2008, elas representaram 99\% do total de 
389.016 $\mathrm{MtCO}_{2}$, das quais $50 \%$ provenientes da valorização energética, $47 \%$ do confinamento técnico e $2 \%$ da valorização orgânica. Tais valores indicam a importância que a prevenção, redução, reutilização e reciclagem assumem na redução das emissões de carbono da gestão de resíduos.

A ação (eixo 2) diz respeito à implementação de medidas internas de redução de emissões, incluindo a definição dos objetivos quantificados e o monitoramento do respectivo cumprimento. Complementarmente, a Lipor se utiliza de mecanismos de compensação para anular emissões inevitáveis, privilegiando ações com elevado potencial de sensibilização pública.

Neste sentido, a empresa definiu metas de redução levando em conta uma linha de base de emissão de $405 \mathrm{kgCO}_{2} /$ habitante por ano, em 2006. No caso, estimou uma meta de redução nas emissões, com relação a 2006, de 12\% em 2012; 16\% em 2016 e 20\% em 2020 (Tabela 2), como esquematizado a seguir.

Tabela 2: Metas de redução de emissões

\begin{tabular}{ccc}
\hline $\mathbf{2 0 1 2}$ & Emissões totais & Emissões per capita \\
$\mathbf{2 0 1 6}$ & $-12 \%$ & $356 \mathrm{kgCO}_{2} /$ hab.ano \\
$\mathbf{2 0 2 0}$ & $-16 \%$ & $340 \mathrm{kgCO}_{2} /$ hab.ano \\
\hline
\end{tabular}

Fonte: Adaptado de Lipor 2010

Finalmente, o "eixo mobilização" é significativo para o sucesso da Estratégia 2M, na medida em que esta depende, em muito, do envolvimento dos cidadãos, pois diferentes atitudes em relação à prevenção e separação de resíduos implicam diferentes níveis de emissões de carbono e diferentes impactos no clima.

A Figura 9 compara como a atitude do cidadão pode influenciar nas quantidades de $\mathrm{CO}_{2}$ emitidas, mostrando que a separação dos resíduos, feita por quem os gerou, já reduz as emissões, à medida que diminui o aporte de materiais para as incineradoras e aterros. Entretanto, é a prevenção da produção e a reutilização de resíduos que reduz substancialmente o balanço de emissões.

A ambição da Estratégia $2 \mathrm{M}$ é então reforçada pela adoção de comportamentos que promovam a prevenção e separação de resíduos. Informar, sensibilizar e mobilizar parceiros e cidadãos para adoção de comportamentos que reduzam as emissões de carbono associadas à produção de resíduos é o objetivo da Estratégia Lipor 2M. 


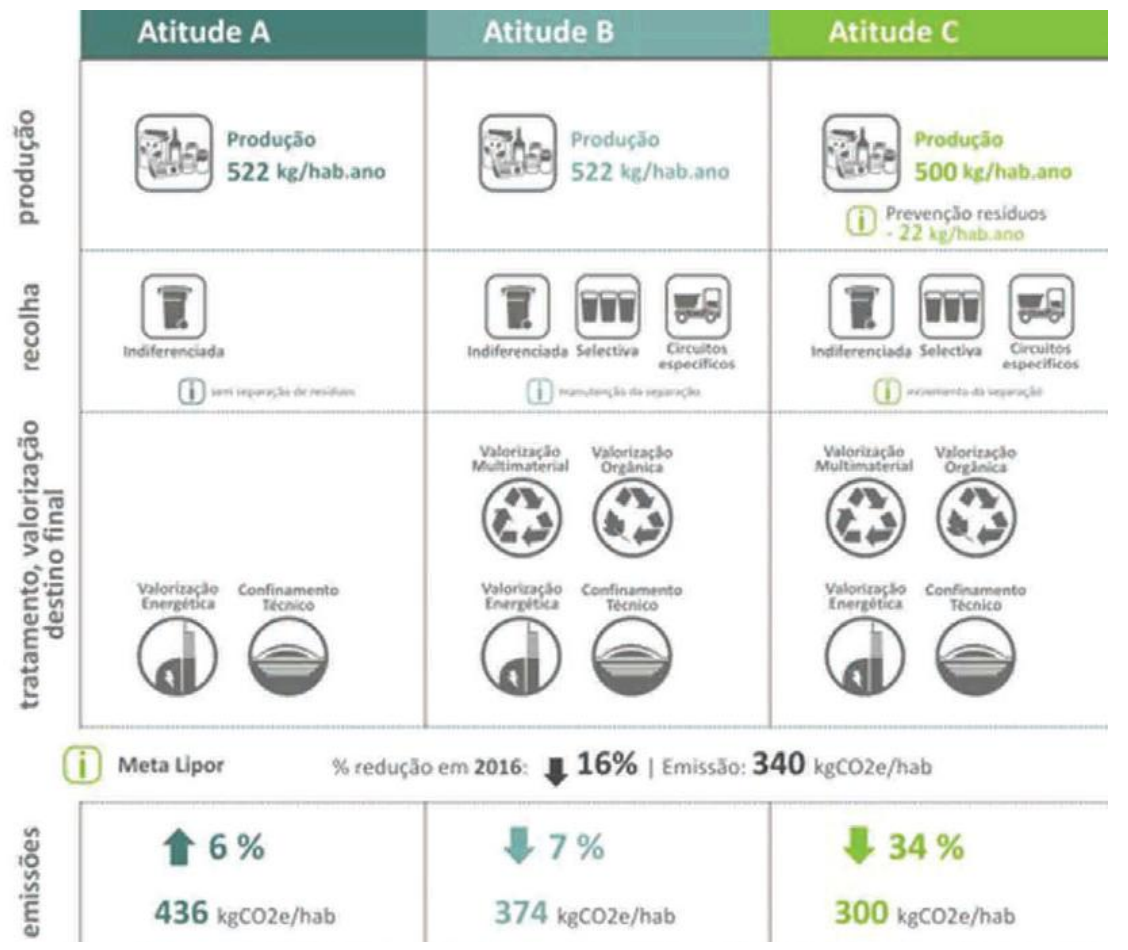

Figura 9: Impactos das diferentes atitudes

Fonte: Lipor 2M, 2010.

\subsubsection{Pay as you throw (PAYT)}

O sistema PAYT apresenta-se como um projeto alternativo que visa estimular novas formas de o cidadão comum encarar a gestão de resíduos, fomentando a reciclagem e o consumo sustentável. Trata-se de uma aplicação do princípio poluidor-pagador, pois cobra do cidadão o custo associado aos resíduos que ele produz à medida que demanda um bem que gerou como resíduos a montante e a jusante.

Os sistemas PAYT diferenciam-se dos atuais sistemas de gestão de resíduos, uma vez que a tarifa variável aplicada à remoção dos resíduos é diretamente proporcional à sua produção. Com isso, evita sua indexação a parâmetros, tais como a área habitacional, o número de residentes por habitação ou consumos de água ou eletricidade, como na maioria dos casos.

Nas comunidades onde o sistema PAYT está implementado verificou-se um aumento significativo nas frações recicláveis recolhidas, assim como uma redução nos resíduos indiferenciados enviados para valorização / eliminação.

Portanto, pode-se concluir que este sistema, em um primeiro momento, garante a:

- Sustentabilidade ambiental, pois materializa a hierarquia de gestão de resíduos definida pela UE, priorizando mecanismos de prevenção na produção de resíduos.

- Sustentabilidade econômica, visto que assegura a aplicação de um custo real na recolha, transporte e deposição final dos resíduos privilegiando o princípio de que quem tem boas práticas ambientais é beneficiado.

- Sustentabilidade social, já que responsabiliza o produtor, fomentando a consciência ambiental e alertando para a necessidade de todos serem parte ativa e interessada em todo o processo de gestão de resíduos.

Deve-se destacar que para a eficiente implementação do PAYT é relevante ter controle sobre a produção de resíduos. Ou seja, um sistema de monitoramento se faz necessário, visto que as tarifas se farão valer, tendo como base o peso/volume dos RSU ou o número de vezes que o resíduo é colocado para coleta. 
Atualmente, a Lipor já colocou em prática tal projeto no Município da Maia, como uma espécie de projeto piloto. Assim, poderá fazer alterações e adaptações quando necessárias, de forma a atingir a melhor estratégia do PAYT. Se for constatado que o projeto atingiu ao propósito da sustentabilidade, em suas diferentes dimensões, o sistema poderá ser implementado em outros municípios.

\section{LEGISLAÇÃO E PRÁTICA DE GESTÃO DE RESÍDUOS SÓLIDOS EM PORTUGAL: ANÁLISE CRÍTICA DOS PROJETOS DE SUSTENTABILIDADE DA LIPOR}

O objetivo deste capítulo é analisar os potenciais fatores da Política de Resíduos Sólidos de Portugal, tendo como exemplo a Lipor e em especial os projetos desenvolvidos pela empresa, tais como a Estratégia $2 \mathrm{M}$ e PAYT.

\subsection{Legislação portuguesa de resíduos sólidos}

A Diretiva Quadro de "Resíduos" 2008/98/CE privilegia uma hierarquia de gestão de resíduos com poucas bases técnica e científica. Não há razão científica, por exemplo, que justifique que a reciclagem material seja sempre uma alternativa preferível ao aproveitamento energético (McDougall et. al., 2001).

A sustentabilidade ambiental da hierarquia é questionada, uma vez que não há comprovação que um processo gere menos impactos que o outro. Novamente usando o exemplo da reciclagem, não é questionável a economia de recursos naturais do processo. No entanto, se as empresas recicladoras se localizarem distantes das fontes geradoras, como em outros países ou continentes, as emissões associadas ao transporte podem superar os benefícios, podendo, em alguns casos, a disposição em aterro ser a prática menos impactante. Por esse motivo, a realização da ACV, e não sua simples sugestão surge como uma boa ferramenta no auxílio à tomada de decisão, visto que leva em conta os impactos gerados durante toda a vida útil do produto, podendo-se comparar de fato as opções e suas cadeias de uso e tratamento.

Além disso, deve-se considerar a questão social como um fator na tomada de decisão do modelo de gestão a ser aplicado na região, pois para uma população a presença de uma incineradora pode ser muito mais incômoda do que um aterro sanitário.

Neste sentido, McDougall et. al. (2001) sugerem que sejam utilizados Sistemas de Gestão Integrada de Resíduos, na medida em que estes combinam os fluxos de resíduos, a coleta de resíduos, tratamento e meios de disposição final, como o objetivo de obter benefícios ambientais, viabilidade econômica e aceitação social. Este sistema deve ser orientado para o mercado, visando a comercialização de seus subprodutos, bem como deve ser flexível, adaptando-se às condições locais e espaciais e, em grande escala, e à base regional. Assim, devem ser igualmente consideradas as quatro vias de tratamento e a disposição de resíduos, conforme descrito no esquema da Figura 10.

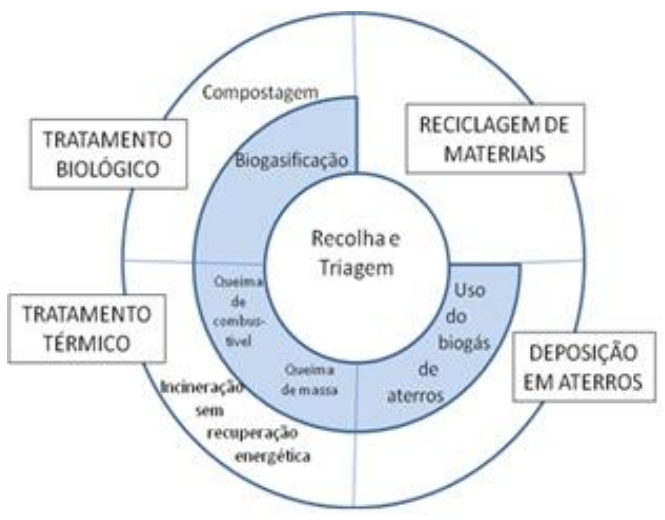

Figura 10: Oportunidades de tratamento e deposição dos resíduos

Fonte: Adaptado de McDougall et. al. (2001)

Revista de Gestão Social e Ambiental - RGSA, São Paulo, v. 6, n. 2, p. 60-78, maio/ago. 2012. 


\subsection{Tarifa de resíduos sólidos}

As estratégias até hoje adotadas para diminuir a produção de resíduos não têm sido muito eficazes. Uma das causas que pode explicar essa ineficácia é a de que a grande maioria dos cidadãos europeus não paga os serviços de coleta e tratamento de RSU, tendo em consideração os custos desses serviços e os resíduos que produzem. No caso, na maior parte dos municípios adota-se um sistema de taxas fixas que tem qualquer correspondência com a quantidade de resíduos produzida (Santos, 2010).

Segundo o Código Regulamentar do Município do Porto (CRMP, 2010), os cidadãos portuenses pagam atualmente pelo serviço de coleta e tratamento de RSU, uma taxa fixa ( $1 € /$ mês) ou indexada ao consumo de água $\left(0,27 € / \mathrm{m}^{3}\right)$. Neste caso, o valor que os cidadãos pagam pelo serviço de coleta de RSU deveria cobrir o custo total da recolha, transporte e tratamento dos resíduos, deduzidos os eventuais proveitos decorrentes da sua valorização, o que raramente acontece em Portugal (PERSU II, 2006). Seguindo-se este princípio, o sistema Pay-As-You-Throw (PAYT) pode representar uma medida eficaz para os objetivos da política de gestão, na medida em que constitui um claro incentivo, por via financeira, para promover a separação na origem e aumentar as taxas de coleta seletiva.

\subsection{Estratégia 2M}

O compromisso de redução voluntária das emissões de carbono da Lipor, firmado pela Estratégia 2M, possui um grande apelo ambiental e faz transparecer as preocupações da empresa com as alterações climáticas e o meio ambiente.

A análise do inventário de emissões foi feita com base nos dados fornecidos nos Relatórios de Sustentabilidade dos anos de 2008 e 2009. A primeira série de dados a ser coletada foi da quantidade de resíduos destinada a cada tipo de tratamento e a quantidade total recolhida em cada ano. A abrangência de quatro anos a partir de 2006 foi escolhida uma vez que a Estratégia 2M refere-se a reduções com base no emitido neste ano. A Figura 11 e a Tabela 3 apresentam os percentuais de cada tratamento e as quantidades em toneladas de resíduos.

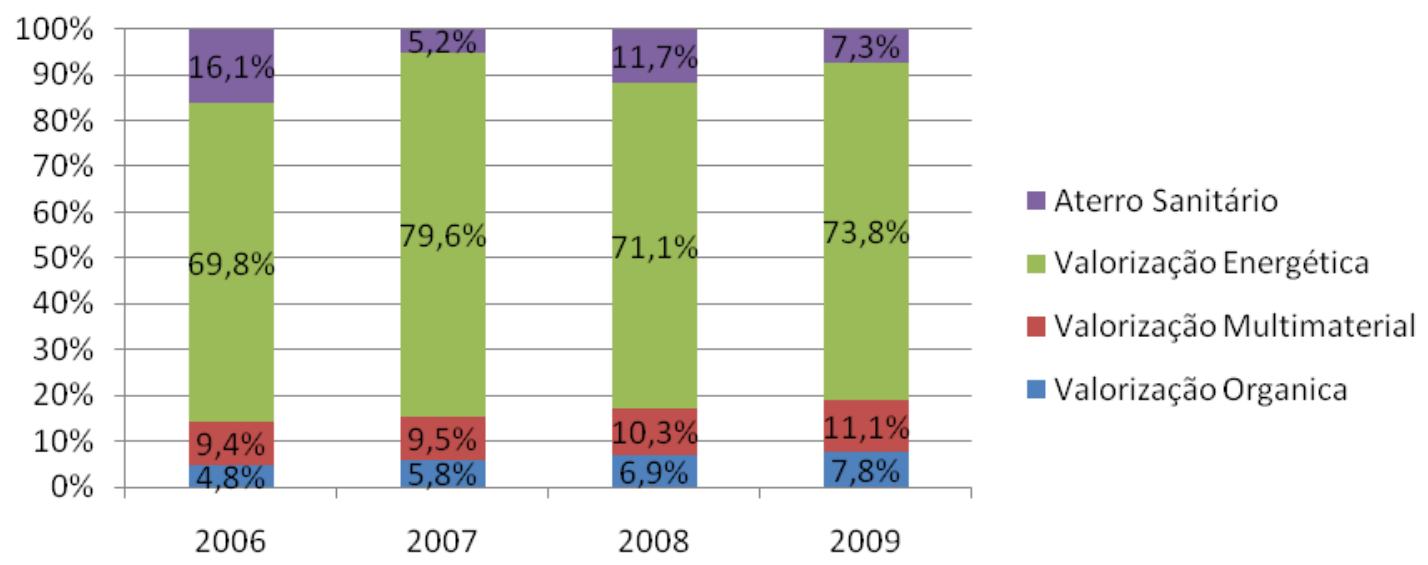

Figura 11: Divisão percentual da quantidade de resíduos sólidos tratados

Fonte: Adaptado dos relatórios de sustentabilidade da Lipor

Tabela 3: Quantidade de RSU tratados entre 2006-2009 (toneladas) 


\begin{tabular}{|c|c|c|c|c|c|c|c|c|c|}
\hline \multirow[b]{2}{*}{ Ano } & \multicolumn{2}{|c|}{ Valorização Orgânica } & \multicolumn{2}{|c|}{$\begin{array}{c}\text { Valorização } \\
\text { Multimaterial }\end{array}$} & \multicolumn{2}{|c|}{$\begin{array}{l}\text { Valorização } \\
\text { Energética }\end{array}$} & \multicolumn{2}{|c|}{ Aterro Sanitário } & \multirow{2}{*}{ Total } \\
\hline & $\begin{array}{c}\text { Total } \\
\text { (toneladas) }\end{array}$ & $\begin{array}{c}\% \text { sobre o } \\
\text { total }\end{array}$ & $\begin{array}{c}\text { Total } \\
\text { (toneladas) }\end{array}$ & $\begin{array}{c}\% \text { sobre } \\
\text { o total }\end{array}$ & $\begin{array}{c}\text { Total } \\
\text { (toneladas) }\end{array}$ & $\begin{array}{c}\% \text { sobre } \\
\text { o total }\end{array}$ & $\begin{array}{c}\text { Total } \\
\text { (toneladas) }\end{array}$ & $\begin{array}{c}\% \text { sobre } \\
\text { o total }\end{array}$ & \\
\hline 2006 & 24.817 & $4,8 \%$ & 48.799 & $9,4 \%$ & 36.2470 & $69,8 \%$ & 83.464 & $16,1 \%$ & 519.552 \\
\hline 2007 & 30.729 & $5,8 \%$ & 49.884 & $9,5 \%$ & 419.388 & $79,6 \%$ & 27.184 & $5,2 \%$ & 527.187 \\
\hline 2008 & 37.145 & $6,9 \%$ & 55.469 & $10,3 \%$ & 383.552 & $71,1 \%$ & 63.308 & $11,7 \%$ & 539.476 \\
\hline 2009 & 42.215 & $7,8 \%$ & 59.965 & $11,1 \%$ & 398.391 & $73,8 \%$ & 39.339 & $7,3 \%$ & 539.912 \\
\hline
\end{tabular}

Fonte: Adaptado dos relatórios de sustentabilidade da Lipor

Os dados apresentados indicam acréscimos percentuais das quantidades destinadas a valorização orgânica e multimaterial, cumprindo, em parte, as legislações que determinam a redução de resíduos orgânicos biodegradáveis em aterros e o aumento da reciclagem. Contudo, a maioria absoluta dos resíduos tratados pela Lipor é destinada a incineração. E, como o aterro é utilizado como apoio à CVE, recebendo os resíduos quando a capacidade da CVE é ultrapassada, além das escórias, nota-se que seu uso varia de acordo com as quantidades incineradas.

A quantidade relativa a cada tratamento e a quantidade total é fundamental para o entendimento de possíveis reduções de emissões de $\mathrm{CO}_{2}$, permitindo verificar se as reduções estão vinculadas a mudança nos processos, ou seja, maior eficiência, ou se houve redução da quantidade total de resíduos coletados, ou ainda se ocorreu uma transferência no modo de tratamento, por exemplo, um resíduo que antes estaria sendo disposto em aterro agora está sendo valorizado na compostagem. A Figura 12 mostra a quantidade $\mathrm{CO}_{2}$ emitida por cada tratamento, e a Figura 13 relaciona esses dados com a quantidade de resíduos destinados a cada tratamento ao longo dos quatro anos.

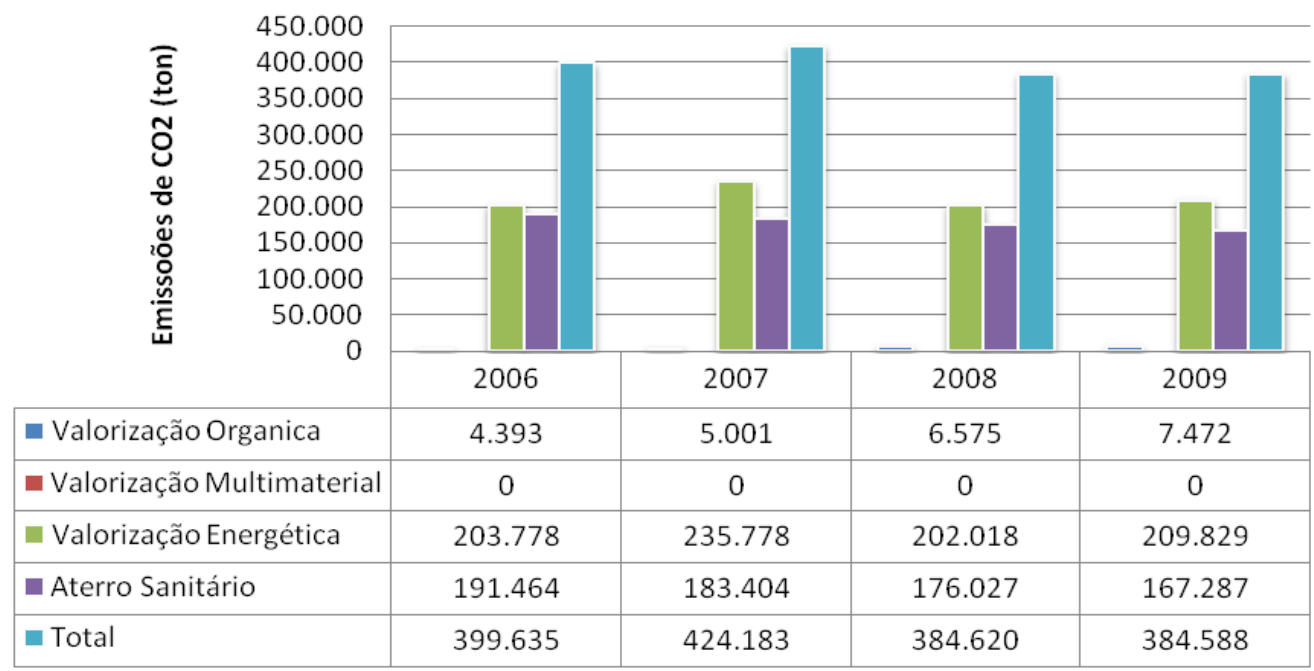

Figura 12: Emissões de $\mathrm{CO}_{2}$ dos diferentes tratamentos de RSU

Fonte: Adaptado dos relatórios de sustentabilidade da Lipor 


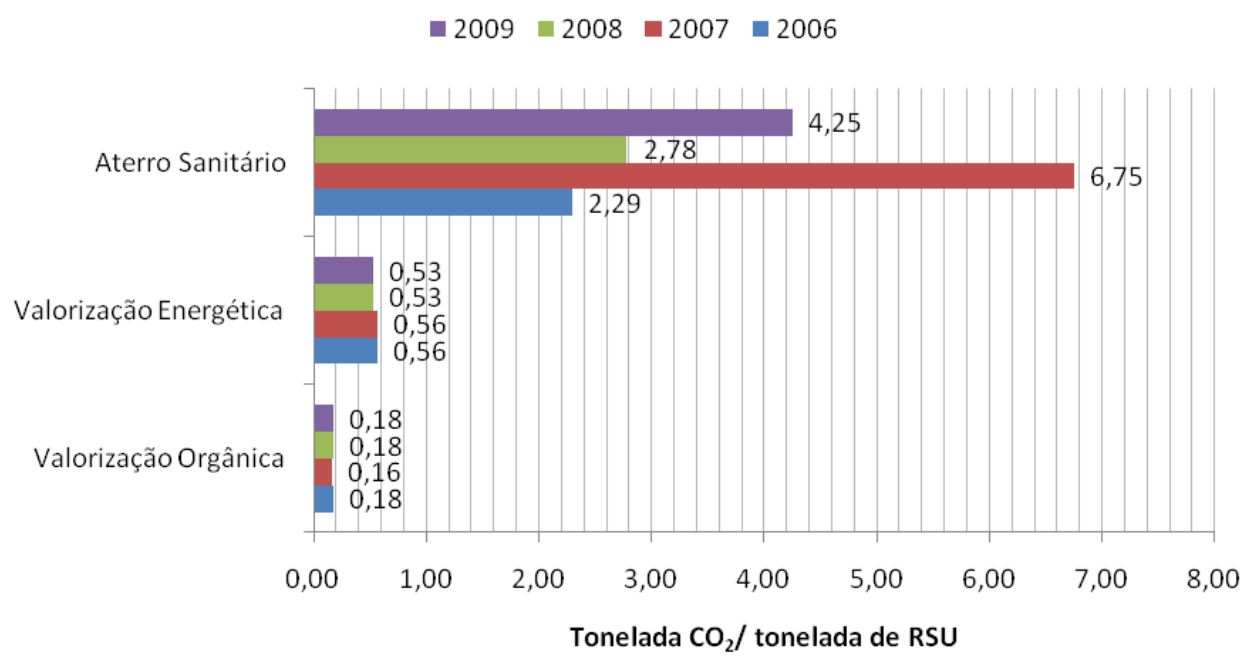

Figura 13: Relação quantidade de $\mathrm{CO}_{2}$ e peso de RSU tratados Fonte: Adaptado dos relatórios de sustentabilidade da Lipor

Nota-se que devido às pequenas quantidades destinadas a valorização orgânica e sua baixa taxa de emissão de $\mathrm{CO}_{2}$, a valorização energética e o aterro sanitário são os grandes emissores de gases.

As taxas de emissões se mantiveram praticamente constantes para a valorização orgânica e energética. A disposição em aterro apresentou um grande salto em 2007, que pode estar relacionado com o menor peso e com o fato de que nos aterros, ao contrário dos outros processos onde as emissões ocorrem durante o processo, a decomposição anaeróbia da matéria orgânica é lenta e emite gases estufas, tais como $\mathrm{CH}_{4}$ e $\mathrm{CO}_{2}$ por longos períodos. Contudo, a grande relevância desta figura é expressar, entre os processos, o mais "eficiente", ou seja, aquele que emite menor quantidade de $\mathrm{CO}_{2}$ por resíduo tratado. Neste sentido, a valorização orgânica é menos poluente que a valorização energética, que, por sua vez, é bem menos poluente que a disposição em aterro.

Deve-se destacar que a Lipor não especifica emissões da valorização multimaterial no seu inventário. Além disso, as emissões provenientes do tratamento/valorização se aproximam bastante das emissões ditas diretas que, segundo o documento da Estratégia 2M, inclui ainda o consumo de combustíveis fósseis e maquinários de transporte e movimentação de cargas. A Figura 14 apresenta, por meio de escala logarítmica, as diferentes classes de emissões.

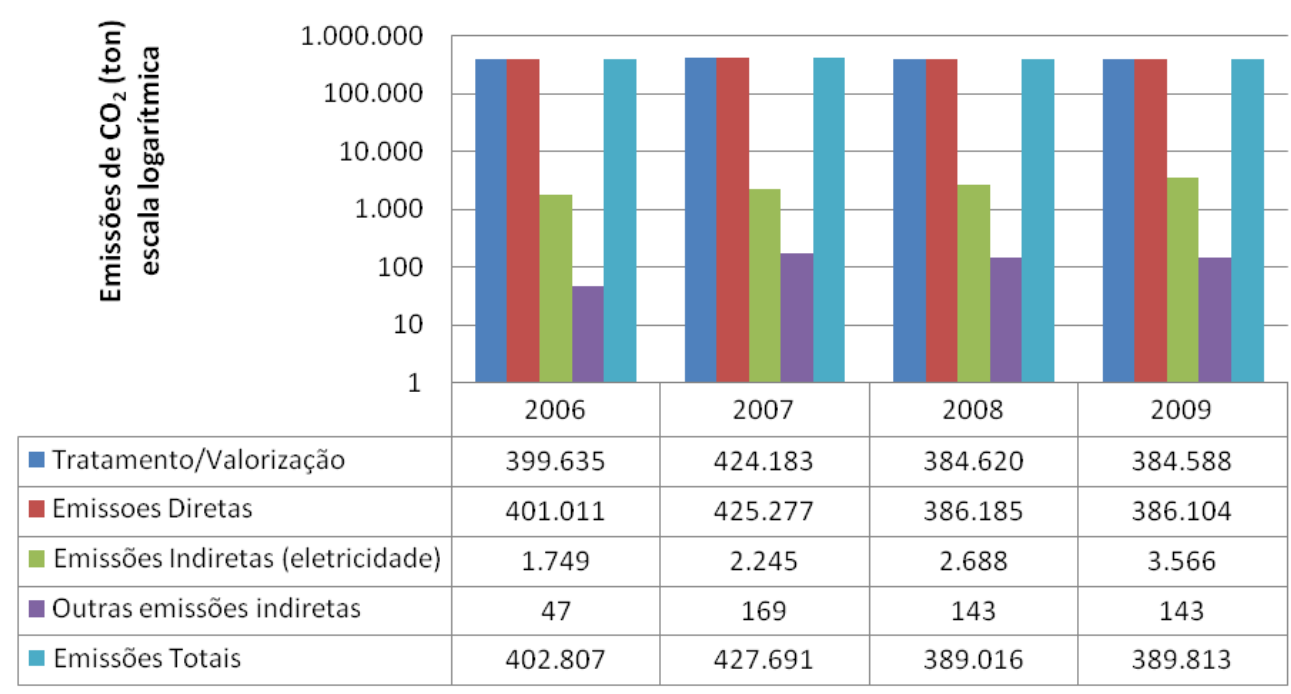

Figura 14: Inventário de emissões de $\mathrm{CO}_{2}$.

Fonte: Adaptado dos relatórios de sustentabilidade da Lipor 
Com as emissões de $\mathrm{CO}_{2}$ concentradas nas emissões diretas, nomeadamente na valorização energética e na disposição em aterros para atingir as metas propostas na Estratégia $2 \mathrm{M}$, as ações da Lipor devem ter como foco os resíduos destinados a esse destino. A Figura 15 mostra a evolução das emissões totais de $\mathrm{CO}_{2}$ da empresa nos últimos quatro anos, e as metas dos anos de 2012 com redução de 12\%; de 2016 com redução de $16 \%$ e de 2020 com $20 \%$, com relação às emissões de 2006.

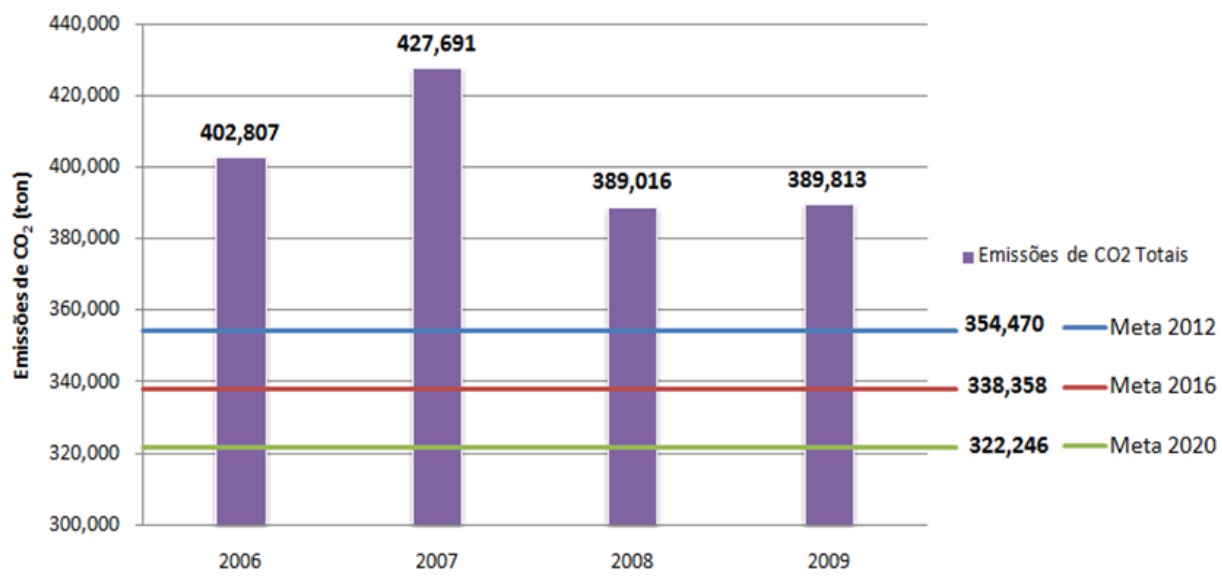

Figura 15: Evolução das emissões de $\mathrm{CO}_{2}$ e metas

Fonte: Adaptado dos relatórios de sustentabilidade da Lipor

Nota-se que, para atingir a meta de 2012, a empresa precisará reduzir em torno de 35.000 toneladas de $\mathrm{CO}_{2}$ em relação ao emitido em 2009, ou seja, uma redução de, aproximadamente, $10 \%$ até o ano de 2012. Neste sentido, convém destacar que em 2008 a Lipor conseguiu reduzir suas emissões em torno de $3 \%$ em comparação a 2006, apesar de um aumento de $4 \%$ na quantidade total de resíduos tratados.

Neste sentido, algumas considerações devem ser feitas sobre a Estratégia 2M. Conforme mostrado na figura 18 , não há uma significativa evolução no que se refere à eficiência do processo de valorização energética, e as emissões em aterros não possuem uma relação linear com as quantidades dispostas. Deste modo, para atingir as metas a empresa precisa reduzir as quantidades destinadas a esses dois processos, ou obter uma redução global dos resíduos coletados.

A transferência de matéria orgânica de aterros para valorização é prevista por lei (Enrrubda) e é uma boa opção para redução. No entanto, a produção de um composto de qualidade requer uma coleta seletiva e complexa desses resíduos, que, por isso, não é, com relação ao processo usual, custo-efetiva. Neste caso, por não ser competitivo, o subproduto necessitaria de incentivos para ser absorvido no mercado. Portanto, no curto prazo, uma grande transferência para essa via de tratamento não é viável.

Por sua vez, o aumento na valorização multimaterial é questionável por alguns fatores. $\mathrm{O}$ principal deles deve-se a não inclusão (ou ao menos não explicitamente) das emissões geradas no processo de triagem dos materiais. Além disso, por ser responsável apenas pela triagem dos recicláveis, a empresa não contabiliza as emissões associadas ao transporte e aos processos industriais de reciclagem. Logo, não necessariamente a utilização da técnica leva a redução nas emissões com relação à disposição dos resíduos em aterros, É neste ponto que deve ser destacada a grande crítica à Estratégia $2 \mathrm{M}$.

Ao incentivar consumidores a adotarem práticas de separação e destinação correta de recicláveis, a empresa diminuiria suas emissões, e assim resolveria seu "problema", uma vez que reduziria as quantidades destinadas à incineração e aos aterros, cumprindo a legislação e suas metas de redução de emissões de GEE. Contudo, as mudanças climáticas são geradas pelas emissões globais de GEE, independentemente da localização e dos responsáveis. Portanto, ao transferir suas 
emissões para as empresas recicladoras, a Lipor corre o risco de promover algo similar ao "jogo de soma zero", não havendo efetiva diminuição da poluição, mas somente ocorrendo a transferência de fontes emissoras, diferentemente do que é apontado em PERSU II (2006), no qual se afirma que há uma maior redução de emissões nas práticas de reciclagem do que na produção energética via incineração.

Além disso, o Eixo 3 da Estratégia 2M, que diz respeito à mobilização para redução de resíduos e de emissões de carbono, convoca a população a mudar suas atitudes em prol do meio ambiente. Entretanto, ao optar pela separação dos recicláveis, a população reduz também os custos da empresa ao diminuir a coleta de indiferenciados e sua sequente incineração, visto que é um processo que apresenta custos superiores aos relacionados à triagem dos materiais passíveis à reciclagem. Sendo assim, apesar da Estratégia $2 \mathrm{M}$ apresentar um grande apelo ambiental, enfatizado pela ação voluntária de redução de emissões, há benefícios econômicos para o sistema, pois atualmente os municípios possuem um déficit orçamentário por não transferirem o real custo da gestão dos resíduos sólidos para a população.

Cabe ainda ressaltar que a definição de metas de redução, baseada em mudanças na atitude da população, não é uma tarefa simples, pois requer um elaborado e bem feito trabalho de conscientização, principalmente quando o objetivo maior é a prevenção e a não geração de resíduos. De modo a ilustrar as dificuldades encontradas neste processo.

\section{CONSIDERAÇÕES FINAIS}

A geração de resíduos é consequência das atividades produtivas humanas. Níveis zero de geração de resíduos e poluição só seriam possíveis se não houvesse atividade produtiva. No entanto, o homem demanda uma série de bens que necessitam ser produzidos e, consequentemente,

descartados. Na atual perspectiva do desenvolvimento sustentável, a gestão dos RSUs pode integrar valores que ajudam a promover sistemas de gestão economicamente viáveis, socialmente justos e ambientalmente corretos.

Este trabalho procurou analisar desde a legislação portuguesa aplicável aos RSU, até o serviço prestado pela empresa Lipor, responsável pela gestão de RSU em oito municípios da Grande Porto.

Portugal segue a Diretiva Europeia que estabelece a hierarquia da gestão de resíduos como ordem preferencial de ação. Neste processo, a prevenção e a redução estão no topo da hierarquia, seguidas pela reutilização. As técnicas de valorização orgânica e multimaterial são consideradas melhores do que a valorização energética. A eliminação em aterro deve ser a última prática a ser considerada. Entretanto, tal ordem não apresenta comprovações técnicas, que é a opção adequada em todas as situações. Sendo assim, a gestão integrada de residuos sugere que deve ser levada em consideração a viabilidade econômica do sistema, as características ambientais e sociais da localidade, além de fatores como necessidade de transporte.

Foram verificados também projetos de promoção do desenvolvimento sustentável, desenvolvidos pela Lipor. Um deles, chamado "Estratégia 2M", é apresentado como uma ação voluntária de redução nas emissões, na qual metas de redução de $\mathrm{CO}_{2}$ são definidas. Considerandose o fato de que o inventário de emissões da empresa não contabiliza as emissões relativas à reciclagem, já que a Lipor executa apenas a etapa de triagem e venda dos recicláveis, ela estaria então transferindo a responsabilidade dessas emissões para outras empresas. Além disso, apesar do forte apelo ambiental do projeto, a empresa também deverá usufruir de benefícios econômicos.

A atual tarifa de RSU em Portugal não garante a sustentabilidade econômica dos sistemas, pois a cobrança de um valor fixo indexado ao consumo de água não cobre os reais custos, além de desestimular a redução e separação adequada dos RSU. O Pay As You Throw (PAYT) coloca-se como alternativa para melhoria do viés econômico dos sistemas de gerenciamento dos RSU, ao se basear no princípio poluidor-pagador em que procura implementar uma taxa de resíduos que reflita o real custo de sua gestão. A Lipor já possui um projeto-piloto que se utiliza do PAYT no município 
da Maia. Efetuando-se adaptações necessárias para aplicação deste projeto em outras localidades, seria possível expandir seus benefícios.

A principal limitação encontrada neste estudo advém da dificuldade em diferenciar, entre as ações propostas pela Lipor, as que, de fato, são voluntárias das que se limitam a cumprir a legislação de resíduos sólidos da UE. Além disso, uma vez que os dados, como os do PERSU, são metas do país e não especificamente da Lipor, o confronto de dados foi dificultado.

Finalmente, cabe destacar que a Lipor constitui uma exceção ao cenário português, visto que sua principal via de tratamento é a incineração, com reaproveitamento energético, enquanto a maioria dos sistemas do país ainda se utiliza de aterros como principal destino para os RSU. Ainda que se questione a sustentabilidade deste sistema, comparativamente ao status quo, a iniciativa da empresa representa um avanço no sentido de se ofererecer uma mais eficiente destinação ambiental aos RSU.

\section{REFERÊNCIAS}

APA, Agência Portuguesa do Ambiente (2009) Sistema de gestão de resíduos urbanos - Dados gerais, valorização e destino final. Recuperado em fevereiro de 2011, de http://www.apambiente.pt.

CRMP, Código Regulamentar do Porto (2010). Recuperado em: fevereiro de 2011, de http://cmpexternos.cm-porto.pt/crmp/.

Egri, C. P., Pinfield, L. T. (2001) Ecologia e meio ambiente. In: Clegg, S.T., Nord, W.R., Hardy, C. Handbook de estudos organizacionais. São Paulo: Atlas.

Gladwin, T. N., Kennely, J. J., Krause, T.(1995) Shifting paradigms for sustainable development: implications for management theory and research. The Academy of Management Review. 20(4), 874-907.

Hopwood, B., Mellor, M., O'Brien, G.(2005) Sustainable development: mapping different approaches. Sustainable Development, .13(1), 38-52.

Lipor (2010) Serviço Intermunicipalizado de Gestão de Resíduos do Grande Porto, Recuperado em: dezembro de 2010, de: http://www.lipor.pt.

Lipor 2M (2010). Estratégia 2M, menos resíduos, menos carbono. Recuperado em: dezembro 2010 , de http://www.lipor.pt/upload/Lipor/ficheiros/Brochura_2M.pdf.

Mcdougall, F., White, P.R., Frank, M., Hindle, P. (2001). Integrated solid waste management: a lifecycle inventory. Blackwell Science.

Mebratu, D. (1998) Sustainability and sustainable development: historical and conceptual review. Environ Impact Asses Rev. n.18, 493-520.

OECD - Organization for Economic Co-operation and Development.(2001) Sustainable development: critical issues. Paris: OECD Publications.

Persu II (2006) Plano estratégico para os resíduos sólidos urbanos 2007-2016. Recuperado em: fevereiro de 2011, de: http://www.maotdr.gov.pt/Admin/Files/Documents/PERSU.pdf.

Purser, R. E.; Park, C.; Montuori, A.(1995) Limits to anthropocentrism: toward an ecocentric organization paradigm? The Academy of Management Review, 20(4), 1053-1089.

REA(2008) Relatório do estado do ambiente. Recuperado em fevereiro de 2011, de http://www.apambiente.pt/divulgacao/Publicacoes/REA/Documents/REA\%202008/REA_2008_23s et.pdf.

Revista de Gestão Social e Ambiental - RGSA, São Paulo, v. 6, n. 2, p. 60-78, maio/ago. 2012. 
Sachs, I.(1993) Estratégias de transição para o século XXI - desenvolvimento e meio-ambiente, Studio Nobel/FUNDAP, São Paulo.

Santos, F. (2010). Implementação de Taxa de Resíduos Individual em Portugal - Caso de Óbidos. Território e Ambiente Urbano, 43.

Shrivastava , P. (1995). Ecocentric management for a risk society. The Academy of Management Review, 20(4), 118-137.

WCED - World Commission on Environment and Development. (1987) Our common future. Oxford: Oxford University Press.

Data do recebimento do artigo: 18/04/2011

Data do aceite de publicação: 10/08/2012 